1995

\title{
Habermas, Goffman, and Communicative Action: Implications for Professional Practice
}

James J. Chriss

Cleveland State University

Follow this and additional works at: https://engagedscholarship.csuohio.edu/clsoc_crim_facpub

Part of the Criminology Commons

How does access to this work benefit you? Let us know!

\section{Repository Citation}

Chriss, James J., "Habermas, Goffman, and Communicative Action: Implications for Professional Practice" (1995). Sociology \& Criminology Faculty Publications. 95.

https://engagedscholarship.csuohio.edu/clsoc_crim_facpub/95

This Article is brought to you for free and open access by the Sociology \& Criminology Department at EngagedScholarship@CSU. It has been accepted for inclusion in Sociology \& Criminology Faculty Publications by an authorized administrator of EngagedScholarship@CSU. For more information, please contact library.es@csuohio.edu. 


\author{
James J. Chriss \\ University of Pennsylvania
}

In his Theory of Communicative Action, Habermas $(1984,1987)$ argues that because Goffman's dramaturgy emphasizes the goal-oriented or strategic nature of actors' self-presentations, it fails to establish the conditions for noncoerced or reasoned communication. After reviewing Habermas's negative reading of Goffman, I assess both Habermas's and Goffman's theories in the context of professional practice and organizational behavior. I suggest that certain programs in the social psychology of organizations, such as Argyris and Schon's (1974) action research, share Habermas's one-sided view of Goffman's actor as an opportunistic, insincere manipulator. This misreading of Goffman results from a fundamental confusion over the ontology and epistemology of "impression management." I conclude that if Habermas's theory of communicative action is to advance further, that is, if it is ever to adequately link with the empirical social world, it must come to more concrete terms with the nature of the presented self.

ver the past two decades researchers in the social sciences and humanities have been taking the "linguistic turn," meaning that they are turning their attention to issues of the self and to theories of communicative conduct or practice. Discussions of the processes or theories of the self are incomplete, however, if they are not formulated or understood within a broader analytical framework. Goffman's (e.g., 1959, 1971, 1974) dramaturgical theory of action, although providing important perceptions and descriptions of the vagaries of face-to-face behavior, does not on its own offer much of

"Direct correspondence to James J. Chriss, Department of Sociology, 3718 Locust Walk, University of Pennsylvania, Philadelphia, PA 191046299. A much abridged version of this paper was presented on August 9 at the 1994 annual meeting of the American Sociological Association in Los Angeles, CA. I thank Hugh Willmott, David Sciulli, John Forester, and Ivar Berg for providing helpful comments on several earlier drafts. I also thank the ASR reviewers for their comments. Much of this paper is drawn from Chapter 9 of my Ph.D. dissertation (Chriss 1994a). For an early cursory statement on the HabermasGoffman problem, see Chriss (1992). [The reviewers acknowledged by the author are Chris Argyris and Ben Agger. $-E D$.] a sense of how these microprocesses are linked to larger social structures.

On the other hand, Talcott Parsons's (1951, 1978) architectonic social systems schema provides a blueprint, a mapping, or a grid for the understanding, or at least the conceptualization of, whole social systems. Parsons attempted to reduce the massive complexity of social systems to a few crucial elements or processes. This analytical gambit amounted to delineating four functional requisites of social systems: adaptation, goal-attainment, integration, and latent pattern-maintenance (AGIL). Then he argued, by sheer force of reason (Parsons's notion of "analytical realism"), that there exists parallel functional processes at all other levels of the social system. ${ }^{1}$

${ }^{1}$ For example, Parsons argued that the process of allocating roles in society was analogous to the internalization, through socialization, of cultural norms and values in the individual. As Parsons (1951) states, "The allocation of personnel between roles in the social system and the socialization processes of the individual are clearly the same processes viewed in different perspectives" (p. 207). Both processes, then, have similar functional significances at their respective levels of generality or specificity, namely that of integration. 
Although Parsons attempted to explain social microprocesses through his AGIL schema, a majority of researchers have not employed his blueprint in their analyses. Parsons's schema is considered by many to be bombastic, overly abstract, and not particularly amenable to empirical testing (but see Lidz 1986). The sense that Parsons's schema is detached from reality-from the empirical social world-led to an avalanche of criticisms beginning in the 1950s and extending until his death in 1979 and even beyond (Dahrendorf 1958; Gouldner 1970; Mills 1959; Wrong 1961).

Much of this criticism of Parsons's program was, of course, concentrated in the academic left, or "radical sociology," and especially in Marxist or neo-Marxist thought. A few observers have suggested, for example, that Parsons's (1937) "voluntaristic theory of action" is notable in that it includes almost no discussion of the works of Marx (Agger 1992; Gouldner 1970). Parsons's program thus offered, at least in the minds of some left-leaning critics, a handy alternative to the Hegelian Marxism prevalent in Europe since the 1920s (Agger 1992:57).

In sociology, the most successful wing of Marxist thought and research has been Frankfurt School critical theory (Kincheloe and McLaren 1994). Horkheimer, Adorno, and Marcuse are some of the thinkers who led the way toward establishing critical theory and extending its influence in sociology, largely through the successes of a number of applied research programs (such as Adorno, Frenkel-Brunswik, Levinson, and Sanford's [1950] study of the authoritarian personality). In extending and updating Marx's legacy, the goal of Frankfurt School thinkers was to identify, uncover, and hopefully ameliorate oppressive social structures or circumstances. Whereas Marx had concentrated primarily on the objective features of oppression, such as those connected with political power and economics, the new critical theory called for a return to philosophy, and even to psychoanalysis, to thoroughly diagnose the pathologies of modern culture.

This emphasis of critical theory continued until the early 1970s, when a new version of critical theory-call it neo-critical theoryemerged, largely through the efforts of Habermas. Habermas's $(1971,1975)$ pro- gram carried forward some elements of the Horkheimer/Adorno version of critical theory. For example, he retained their critical view of positivism and their goal of establishing a new theory of knowledge, which would, in dialectic fashion, take into account the social, historical, and cultural contexts within which that knowledge is formulated and accepted (i.e., the sociology of knowledge; see Dahl 1995).

But departing from the original Frankfurt School tradition, which was largely skeptical of the ability of established science to contribute to the good life, Habermas aimed to rescue science and the Enlightenment-inspired force of reason through a search for the foundations of knowledge (Bottomore 1984). Habermas argued that if we are indeed interested in identifying and eradicating oppressive social structures, we must establish a foundation or basis upon which we can say, with some degree of certainty, what is or is not a liberative or oppressive social structure. This understanding of social structure can be forged only if critical theorists turn their attention back to conceptualizing entire social systems, focusing once again on certain crucial elements heretofore neglected in the social science literature.

This attention to systems theory led Habermas inexorably to an analysis of the works of Parsons. Habermas (1987) states, for example, that "no theory of society can be taken seriously today if it does not at least situate itself with respect to Parsons" (p. 199). This is not to say, of course, that Habermas was wholly enamored of Parsons's theory. Habermas argues that Parsons's work displays a deep internal tension between the idealist tradition of social action and the positivist tradition of social systems. In essence, Parsons's theory never successfully coupled "system" to "lifeworld" (but see Munch 1993). ${ }^{2}$ This is because Parsons was

\footnotetext{
2 Habermas (1984:82) argues that, for analytical reasons, we need to distinguish between "world" and "lifeworld," especially with regard to discussing the "rationalization of the lifeworld." As human beings we rely, often in taken-for-granted fashion, on a cultural stock of knowledge which, because it is already intersubjectively shared, both forms the background for communicative action and provides the foundation for our routine social doings. The
} 
generally inattentive to talk-to speech theory or to linguistic analysis, more generally. Parsons chose instead to attend to broad conceptions of culture, as in the culture, personality, social system triad, and this focus kept his theory of social action suspended within the system or functionalist side of the analytical divide.

On the other hand, according to Habermas, Goffman's dramaturgical theory, although giving attention to social action or lifeworld processes, is suspended in the idealist tradition, and therefore it was never in a position to link adequately to systems theory. Goffman's mistake was that he never understood, perhaps never realized, that talk itself could contain the potential for a universal foundation for critical theory that could traverse the lifeworld-systems divide. This foundation is, as Habermas argues, the universal validity claims inherent in all speech (to be discussed more thoroughly below). ${ }^{3}$

\section{COMMUNICATIVE ACTION IN ORGANIZATIONAL CONTEXT}

Goffman's work stands on its own as a representation of the lifeworld processes of social interaction and face-to-face behavior. If we are ever to reconcile Parsons's systems theory with Goffman's work on the microprocesses of communication, it seems that Habermas's theory of communicative action may serve well, as it has assimilated crucial aspects of Parsons's schema.

"lifeworld" is an unthematized realm that, suffused as it is with shared cultural knowledge, allows us to refer thematically to something that actually exists in the objective world. For an extended critique of Habermas's formulation of lifeworld, see Rosenthal (1992).

${ }^{3}$ Habermas's theory of communicative action can be thought of as a meso theory providing links from the macro or systems analytical realm to the micro or lifeworld analytical realm. House, Rousseau, and Thomas-Hunt's (1995) meso theory of organizational behavior, although not drawing from Habermas per se, nevertheless shares some affinities with Habermas's program, such as their criticism of prevailing general psychological theories in the field of organizational behavior (OB), which tend to be context-free and rarely take into account macro or structural variables.
Any further discussions of Goffman, Parsons, Habermas, and their interrelation at this high level of theoretical abstraction runs the risk of disintegrating into confusion, into something even less than a patchwork of ideas. Thus, I move now toward a concrete area of concern to facilitate this discussion of communicative action: professional practices, such as planning, consulting, and evaluation.

I choose the substantive area of professional practice because I have worked as a consultant (mainly in business and education) and evaluator (in program planning and evaluation with philanthropic organizations), and of course I did much of this work through observing talk in formal (business or organizational) settings. For example, consultants, planners, or evaluators may be hired by a business to observe the nature of interactions taking place between personnel across various organizational hierarchies (Stein 1994).

Organizations hiring consultants to do such work are concerned, of course, with the bottom line-improving organizational communication, performance, or perhaps even morale. ${ }^{4}$ Sociologists familiar with Habermas's or Goffman's works may well recognize this particular organizational problem as one of "systematically distorted communication" (Habermas 1987). The goal of the consultant in such a case is to recommend actions for improving the organization's com-

${ }^{4}$ With respect to morale, an organization may hire a consultant if there is a widespread organizational perception that employee morale is low or that managers are not effective in motivating in their employees a sense of organizational pride, loyalty, or teamwork. The literature on problems and issues of this sort falls somewhat outside the bounds of sociology per se, residing instead in literature on organizations and especially management. The practice of compelling employees to demonstrate loyalty to a particular set of organizational values has received a scathing critique from Willmott (1993), who states:

Especially in cases where insecure, fashion-conscious management strives to 'modernize' its practices, aided and abetted by consultants who prey upon managers' vulnerability, a paradoxical consequence of culture-strengthening programmes is a further degradation and distortion of communication as employees instrumentally adapt their behaviour to conform with the relevant corporate code. (P. 536) 
municative practices (Felts 1992; Hakel 1994).

A few professional planning consultants, such as Forester $(1989,1992)$ and Schroyer (1973), have made explicit connections between their day-to-day consulting work and Habermas's theory of communicative action. Other scholars, such as Sciulli (1992a) and Frankford (1994), are actively working on programs that attempt to implement or assess Habermas's ideas within the context of professional or business practices. For the most part, however, the theory of communicative action remains distant from practice. Frankford (1994) and others have suggested that although critical theory's major goal has always been to link theory to practice, attempts such as Habermas's to facilitate such links have not been successful. Just as with Parsons's AGIL schema, Habermas has faced the difficulty of making his abstract theory relevant to the empirical social world.

The guiding idea of my paper is that Goffman's observations on face-to-face interaction, and especially his taxonomy of verbal presentations of self, may be just the sort of empirically-grounded research to provide links from theory to practice. I return in the next section to the case of business consulting, specifically Argyris and Schon's (1974) program of "action research." I illustrate that Habermas's theory of communicative action is relevant even in those cases where the practitioners themselves may be unaware of such theory-practice links. ${ }^{5}$ Thus, I illustrate

${ }^{5}$ Until 1985, Argyris and his associates (Argyris, Putnam, and Smith 1985) made no explicit mention of the relevance of Habermas and critical theory to their own work, such as in the following quote:

Action science is not alone in advocating that communities of inquiry be enacted in communities of practice. This formulation also seems appropriate to critical theory as articulated by theorists of the Frankfurt School. Habermas speaks of creating conditions that approximate the 'ideal speech situation,' which would allow human beings to come to a rational consensus about how to conduct their affairs. To our knowledge, however, Habermas has not devoted his energies to creating such conditions in the real world. (P. 35; italics added)

For an interesting discussion that compares and contrasts Habermas's critical theory with action research, see Ledoux (1981). the potential applicability of Habermas's theory within business and professional settings where consultants are paid to observe organizational actors' social and verbal interaction.

I address a final issue, however, before continuing. One could very well argue that my attempt to analyze Habermas, Goffman, and issues of communicative action within the context of organizations is fatally flawed because, by their very nature, formal organizations and other administrative entities are based, not on communicative rationality, but on purposive and instrumental rationality. Cooke (1994), for example, notes that "the administrative system does indeed represent a mechanism of action coordination external to the lifeworld" (p. 20).

Habermas (1987) admits that even within formal organizations a number of routine interactions between organizational members are connected via the mechanism of mutual understanding - that is, on some crucial levels communicative action is assured or at least made possible between these organizational actors. As Habermas (1987) continues,

Members of organizations act communicatively
only with reservation. They know they can
have recourse to formal regulations, not only
in exceptional but in routine cases; there is no
necessity for achieving consensus by commu-
nicative means. . . Innerorganizational rela-
tions constituted via membership do not re-
place communicative action, but they do
disempower its validity basis so as to provide
the legitimate possibility of redefining at will
spheres of action oriented to mutual under-
standing into action situations stripped of
lifeworld contexts and no longer directed to
achieving consensus. (Pp. $310-11$ )

Although I am sympathetic to criticisms that, following Cooke (1994) and Habermas (1984, 1987), point out the instrumental, possibly even coercive nature of organizations, I argue that there are equally pernicious impediments to engaging in noncoerced or reasoned communicative interaction within the boundaries of the lifeworld itself. Granted, actors may very well be ethically neutralized by the formal-legal constitution of action systems typical of organizations-this amounting to a distortion of lifeworld processes via the incursion of systems imperatives. Nevertheless, there always exists the 
possibility that certain forms of action, such as strategic action, although emanating from the lifeworld itself, are nevertheless parasitic on communicative action, thereby hampering actors' ability to reach understanding. ${ }^{6}$

With this caveat in mind, let us turn now to a discussion of Argyris's action research.

\section{ARGYRIS, SCHON, AND ACTION RESEARCH}

For several decades Argyris, Schon, and other researchers have been involved in what is variably described as "action research," "action inquiry," or "action science," a program for integrating thought and action, especially in the context of professional practice (Argyris 1993a, 1993b; Argyris et al. 1985; Argyris and Schon 1974, 1989; Schon 1983; Torbert 1991; Whyte 1991). Those who work as evaluators, planners, consultants, psychiatrists, lawyers, architects, caseworkers, and so forth, spend years receiving formal and rigorous training in a variety of diagnostic techniques that give them efficacious means for assessing and intervening in their world.

Argyris and Schon (1974) provide the following account of the logic underlying their own action program:

All human beings-not only professional practitioners-need to become competent in taking action and simultaneously reflecting on the action to learn from it. The following pages provide a conceptual framework for this task by analyzing the theories of action that determine all deliberate human behavior, how these theories of action are formed, how they come to change, and in what senses they may be considered adequate or inadequate. (P. 4)

In the authors' assessment, then, all deliberative action, whether conducted by professionals in a work setting or by laypersons in the course of their everyday lives, is based upon some theory of action or conduct, however tacit or unthematized this theory may be in the minds of actors. The authors suggest that one of the primary goals of their program is to help identify what they call "theories-in-use," that is, the actual assumptions,

${ }^{6}$ As we shall see later, Habermas argues that dramaturgical action is parasitic on communicative action as well. knowledge, orientations, and strategies undergirding and informing the actual social practices of individuals in given situations. As Argyris and Schon (1974) state, "Theories-in-use are means for getting what we want. They specify strategies for resolving conflicts, making a living, closing a deal, organizing a neighborhood-indeed, for every kind of intended consequence" (p. 15).

Argyris and Schon are careful to distinguish theories-in-use from mere "espoused theories," the latter being those theories of action to which actors or organizations give written or spoken allegiance. The idea is that we cannot be certain of deriving a person's theories-in-use simply by asking why he or she did $\mathrm{X}$ or $\mathrm{Y}$ under condition $\mathrm{Z}$; a person may not even be aware of incompatibilities between their espoused theories and theories-in-use. Likewise, an organization may have a written code of directives or a formal manifest pertaining to organizational goals or purpose: yet their overtly stated positionthe organization's "espoused theory"-may not align with actual organizational practices. $^{7}$

Argyris and Schon's (1974) research points to a particular model that accounts for persons' typical theories-in-use, which they refer to as "Model I." This model designates (1) a group of governing variables, or the goals research study participants strove to achieve; (2) action strategies, these being the actual strategies participants adopted; (3) consequences for the behavioral world; and (4) consequences for learning.

\footnotetext{
${ }^{7}$ Argyris and Schon, citing Scott (1969), illustrate the incompatibility between espoused theories and theories-in-use among workers in an agency for the blind. The organization's official position, as represented in written documents and employee testimony (its espoused theory), holds that "the blind are potentially independent, that agencies for the blind function to help the blind realize that potential. The theories-in-use, however, assume that the blind are basically dependent on the agencies, that it is a function of the agencies to sustain the dependence through continuing service, and that the function of a blind person is to adapt to life in an agency setting" (Argyris and Schon 1974:8). Note also that this idea parallels Goffman's discussions of virtual versus actual identity (1963b) and total institutions (1961a).
} 
Particularly important are the consequences for the behavioral world resulting from the various action strategies employed by research study participants and the governing variables underlying these strategies. For example, if an actor's primary orientation to the world is to define goals and try to achieve them (the famous ends-means schema), then a typical action strategy would be to design and manage the environment unilaterally (e.g., by being persuasive or by appealing to larger goals). When actors find themselves in such situations or perceive situations in such a light, the consequences for the behavioral world are such that actors are seen by others as defensive (e.g., having to defend a particular line of action or provide rationale), as inconsistent (e.g., in cases where the chosen means don't appear to align well with desired or stated ends), as competitive, controlling, manipulative, or any number of other negative consequences.

The implications of Model I, according to Argyris and Schon (1974), is that, other things being equal, behavior is typically defensive and ultimately dysfunctional. This defensiveness is passed on across generations, as children are socialized into or learn Model I behavior from their parents, peers, and significant others insofar as the behavioral worlds of the family, school, and elsewhere conform to the assumptions of Model I (Argyris and Schon 1974:82). As Argyris and Schon (1974) state,

Aduits programmed with these [Model I] values tend to create human relationships that emphasize competitiveness, withholding help from others, conformity, covert antagonism, and mistrust while deemphasizing cooperation, helping others, individuality, and trust. (P. 83)

The authors then make an assertion that has grave implications for my work on Goffman, Habermas, and communicative action: Because these dysfunctional Model I values are embedded in our culture and remain there as unseen or unthematized aspects of daily life, they are "confirmed" by societal members and act as real, authentic, natural, or inevitable guidelines for directing groups or individuals in their dealings with one another. Hence, "Interpersonal diplomacy, being civilized, withholding feelings, and suppressing anger and hurt are but a few com- mon examples of what individuals are taught to do to help maintain harmony in interpersonal relationships" (Argyris and Schon 1974:83).

Argyris and Schon argue that the tools of interpersonal diplomacy - things like deference and demeanor, politeness, embarrassment, norms of etiquette, face work, remedial and supportive interchanges, accounts and apologies, tolerance, access rituals, and role distance (Goffman 1953, 1959, 1961 b, 1963a, 1967, 1969, 1971, 1974, 1981)-actually support Model I, thereby sustaining and perpetuating the dysfunctional behaviors associated with it. In fact, from the perspective of Argyris and Schon, Goffman's lifelong work was dedicated to unearthing, describing, and systematizing humanity's destructive but "natural" Model I behavior. ${ }^{8}$

What this implies, then, is that Goffman's description of the interaction order, and the vast array of interpersonal rituals contained therein, amounts to documenting the ways persons go about the business of living and coping in a world of "pseudo-authenticity." Model I generates and regenerates a state of pseudo-authenticity, especially insofar as persons tend to minimize negative feelings and their expression.

As we have seen, then, the governing variables of Model I consist of competitive, win/

${ }^{8}$ I argue (Chriss forthcoming) that the behaviors that Argyris and Schon describe as self-sealing, defensive, and ultimately destructive actually embody the negational self. The negational self is a self by default in that most public declarations of self amount to specifying what the self is not. This can be accomplished through role distancing or through self-effacement and modesty about the self. Through these behaviors persons attempt to demonstrate the ideals of a well-demeaned individual. Habermas (1984), too, sides with Argyris and Schon in emphasizing truth-telling as part and parcel to reasoned communication, thereby tending to cast politeness and other etiquette norms into the realm of the irrational since they can work to mask persons' truthful assessments of a situation. Kingwell (1993:392) warns, however, that any reconstruction of rational presuppositions in communication, such as embodied in Habermas's theory of communicative action, would have to include those propositions associated with politeness, especially as specified by Grice (1975) and Goffman (e.g., 1959, 1967, 1963a, 1971). 
lose, rational, and diplomatic behaviors that are "self-sealing." These are examples of what Habermas $(1984,1987)$ would call "systematically distorted communication." For most large-scale organizations, distorted communication is a day-to-day, operational reality. As Forester (1989) explains,

Whether in the public or private sector, organizations are not egalitarian utopias; differences of status, power and authority, information and expertise, interests and desires abound. Those realities-including the incompetent manager, the arrogant section head, the misinformed staff analyst, the fight between developer and regulator-cannot be wished away. (P. 8)

It is no great revelation that much of the dysfunctional Model I behavior with which Argyris and Schon are concerned is expressed or expressible in talk. Likewise, it is no surprise that the corrective measures which they propound-as specified in their "Model II" program of theories-in-use-are targeted at organizational communication and face-to-face behavior.

Argyris and Schon (1974) suggest that Model II's governing variables are an improvement over Model I's because they are not self-sealing, but instead tend to permit more effective testing of interactants' assumptions and greater learning about one's effectiveness as a communicator and/or interpreter. For example, the primary governing variable of Model II, namely maximizing valid information, means that an actor provides others with directly observable data so that others may make valid attributions about the actor (Argyris and Schon 1974:86). The organizational consultant's job, then, is to show organizational actors how to make the transition from Model I-self-sealing behavior-to Model II-open and honest behavior based on maximizing valid information, maximizing free and informed choices, and maximizing internal commitments to decisions made. Argyris and Schon spell out in some detail the steps that instructors typi-

\footnotetext{
9 "Self-sealing" behavior is behavior that closes off public testing of the assumptions of one's or other's theories-in-use, thereby reducing learning and hence freezing actors in static and potentially destructive worlds. An example of the self-sealing process is as follows. Actor $A$ believes that actor $B$ is defensive: If $A$ cannot test this belief
}

cally take in helping participants actually learn Model II behavior (see 1974:110-136).

The differences between Habermas and Goffman is thus illuminated by the analysis of the work of consultants, especially those who are considered experts in the observation of face-to-face interaction in a variety of settings-often organizational ones.

The empirical context thus established, I now return to Habermas's theory itself. In an attempt to describe and clarify the methods of reasoning employed by Habermas in his Theory of Communicative Action (1984, 1987), Baldamus (1992:100) provided a citation analysis of that work. Not surprisingly, Baldamus found that of the 220 authors cited by Habermas, the top 5 were (by total number of citations) Parsons (180), Weber (140), Durkheim (76), Mead (75), and Marx (69). Much further down the list, cited only 4 times, is Goffman. I evaluate Habermas's brief treatment of Goffman and suggest the ways in which Goffman's theory might help connect Habermas's overtly analytical theory of communicative action to the empirical social world.

\section{HABERMAS ON THE CONCEPTS OF TELEOLOGICAL, NORMATIVE, DRAMATURGICAL, AND COMMUNICATIVE ACTION}

Habermas (1984) defines "communicative action" as "the interaction of at least two subjects capable of speech and action who establish interpersonal relations (whether by verbal or by extra-verbal means)" (p. 86)..$^{10}$

and if $A$ acts according to his hunch, B probably wonders why $A$ is behaving in this way. Therefore B acts cautiously. A senses B's caution and may interpret it as evidence that $B$ is indeed defensive. A believes that if he were to reveal his feeling that $B$ is defensive, his relationship with $B$ would become less manageable. A's reluctance to confront B means that B in turn need not confront the incongruity between B's espoused theory and his theory-in-use. But also as a result, A's behavior is incongruent with his values. The norms supporting incongruity and minimizing expression of negative feelings are reinforced, thereby exacerbating $A$ 's negative or uncertain feelings about B (Argyris and Schon 1974:77).

10 This obviously excludes so-called "selftalk." Goffman $(1978,1981)$ deals with specific 
Obviously, language is itself prominent in Habermas's model-it is the medium through which individuals interpret each other's plans of action while negotiating definitions of the situation. Ideally these negotiations, if they are to lead at all to a final (even if only provisional) definition of the situation, must first and foremost define consensus among the participants.

This process of achieving understanding through language is for Habermas the defining problem in the theory of communicative action. As Habermas (1984) explains, "The concept of reaching an understanding suggests a rationally motivated agreement among participants that is measured against criticizable validity claims" (p. 75). Habermas's theory of communicative action, then, attempts to treat rationality from a universalistic perspective. That is, in attempting to delineate the normative foundations of a critical theory, Habermas suggests that these essential concrete norms are implicit in the validity claims of all speech.

Habermas then expands this provisional concept of communicative rationality by analyzing the ontological assumptions of rationality embedded in a variety of social-scientific theories of action. Habermas (1984:85) suggests that this "profusion of action concepts" can be reduced in essence "to four basic, analytically distinguishable concepts" or theoretical traditions: (1) teleological action, (2) normatively regulated action, (3) dramaturgical action, and (4) his own communicative action.

Habermas evaluates the worthiness and sophistication of the four theoretical perspectives on action with respect to how each satisfies the criteria of a three-world model. Habermas's (1984:95) three analytical worlds correspond to the three ways social actors relate to the everyday world, namely, objectively, socially, and subjectively. This threefold relation of communicative actors to their world identifies different forms or di-

forms of self-talk, such as imprecations and curses (e.g., "ouch!," "damn!," "jeez!," "oops!"). Habermas (1979) chastises Goffman, however, for lumping together identity-threatening acts, which are authentic emotional-expressive instances of self-talk, with spill cries, such as those mentioned above, which are more impulsive and not overtly calculated as face-saving devices. mensions of understanding that members of a society gain as a result of their interaction with others as well as through other routine social practices. Habermas argues that the four theoretical perspectives on action vary in the extent to which each is able to illuminate these relations. He lists these theories in rank order: Teleological action is at the weak end of the explanatory spectrum, and progressing to the most efficacious of the theories, Habermas's own communicative action theory is at the strong end.

\section{Teleological Action}

Since teleological concepts of action-such as those of utilitarianism, behaviorism, or rational-choice theory-emphasize primarily the strategic or goal-oriented calculations actors employ in pursuing courses of action, Habermas suggests that this concept can only account for one world, namely the objective world. As the actor is engaged in a decision calculus that takes into account the elements of his or her action options in relation to the constraints and exigencies of the objective world, the intended effect in the world or the results of his or her strivings will in the end be judged a success or failure according to criteria of truth and efficacy (Habermas 1984:87). The implications of teleological theory is that action, as realized through the cognitive processes of a knowing subject, is represented only as a relation between the actor and a world. At the level of its ontological presuppositions, then, teleological action operates from a highly demarcated, and for Habermas's purposes, insufficient one-world concept.

\section{Normatively Regulated Action}

Whereas teleological action operates from a limited one-world perspective, normatively regulated action (such as Parsons) presupposes relations between an actor and two worlds (Habermas 1984:88). Actors depicted in the normatively regulated concept of action are endowed with a "motivational complex" in addition to teleology's lower-level "cognitive complex." The motivational complex makes norm-conformative behavior possible in that actors judge whether or not the actions of themselves or another actor are in 
accord with existing norms (Habermas 1984:89). Beyond providing judgments of the extent to which actions are successful or unsuccessful in relation to the objective world, the normatively regulated model of action also provides for judgments of an actor in his or her relation to the social world, insofar as the actor is able to comply with (or is unable or chooses not to meet) the normative expectations of the members of his or her social group. This is a two-world model because, as Habermas (1984) explains, the concept of norm-conformative action "presupposes that the agent can distinguish the factual [objective] from the normative elements of an action situation, that is, conditions and means from values" (p. 90).

\section{Goffman's Dramaturgical Model of Action}

Habermas then discusses the concept of dramaturgical action. Like normatively regulated action, dramaturgical action provides a two-world model, the two worlds comprising the objective and subjective dimensions of an actor's relation to the world. Goffman's actor "works the system for the enhancement of self" through self-presentation and impression management. This idea is, for Habermas, strongly reminiscent of the kind of goalorientedness characteristic of teleological (strategic) action. As Habermas (1984) states, "The dramaturgical qualities of action are in a certain way parasitic; they rest on a structure of goal-directed action" (p. 90).

In addition to the objective world, dramaturgical action depicts a subjective world; actors involved in self-presentation must form a "visible public" with regard to their audience. For the theorist, then, this model of action opens up a subjective world of actors making "staged presentations" before a group of others. In other words, we peer inside the "black box" of the subjective workings lurking behind and animating an actor's overt behavior. As Habermas (1984) explains, the concept of dramaturgical action suggests that "the actor is oriented to his own subjective world in the presence of his public" (p. 93).

Important to note here is that unlike the concept of normatively regulated action, Habermas argues that dramaturgical action does not allow for understanding or explaining the social world. In fact, he suggests that all three of the aforementioned action concepts are deficient with respect to at least one of the three worlds.

Although each of the concepts (teleological, normatively regulated, and dramaturgical action) presupposes the importance of language in explaining an actor's relation to the world, Habermas suggests that only communicative action incorporates language as a medium for reasoned or noncoerced actiona medium through which actors can actually gain understanding and consensus as members of a societal community. As Habermas (1984) explains,

Only the communicative model of action presupposes language as a medium of uncurtailed communication whereby speakers and hearers, out of the context of their preinterpreted lifeworld, refer simultaneously to things in the objective, social, and subjective worlds in order to negotiate common definitions of the situation. (P. 95)

It is my position that Habermas's diagnosis of the deficiencies of teleological, normatively regulated, and dramaturgical concepts of action in explicating certain dimensions of his three-world model is for the most part sound. However, I explore further Habermas's judgment that dramaturgical action fails to adequately specify actors' relations to the social world. I believe, in fact, that Habermas's theory of communicative action may be fruitfully recast through the prism of Goffman's (1974) frame analysis, especially with reference to "The Frame Analysis of Talk" (Goffman 1974, chap. 13:496-559). ${ }^{11}$ Before moving on, however, I first review

\footnotetext{
"Because Habermas published Communicative Action in 1981 (translated from German in 1984), it is perhaps the case that he had not yet read Goffman's Frame Analysis, which was first published in 1974 (and translated into German in 1980). Habermas never cites Frame Analysis, and it is hard to imagine that he would have come to the same conclusions regarding the inadequacies of dramaturgical action for his own theory of communicative action had he been familiar with its major arguments. However, Habermas (1979) was familiar with a paper of Goffman's-_'Response Cries" (Goffman 1978)-which later appeared in an edited volume on human ethology (von Cranach, Foppa, Lepenies, and Ploog 1979) and then was included in Goffman's Forms of Talk (1981). However, Goffman does not refer to or mention Frame Analysis anywhere in that paper.
} 
Habermas's discussion of validity claims and the rationality assumptions underlying communicative action.

\section{COMMUNICATIVE ACTION, RATION- ALITY, AND VALIDITY CLAIMS}

To reiterate, Habermas is concerned first and foremost with an analytical program that, through the generative assumptions of universalizable ethics (norms) and social actors' capacity for moral reasoning and rationality (Benhabib 1992:24), attempts to delineate criteria for and the possibility for noncoerced, or communicative, action. The problem of rationality is thus reintroduced in Habermas insofar as the conditions for such a communicatively achieved, reasonable consensus among actors must be grounded in the possibility of actors' communicative rationality, this being "the competency to argue and the imperative of responsibility [through language]" (Hinkle 1992:317; also see Hayim 1992).

Habermas's attempt to designate criteria for noncoerced, or communicative, action hinges on the explication of three validity claims that represent the binding force of communicative acts. A speaker raises all of the following validity claims with his or her utterances, as every speech act could be contested on the following grounds:

(1) Hearer can contest the normative rightness of the utterance (social world).

(2) Hearer can contest the subjective truthfulness of the utterance (subjective world).

(3) Hearer can deny that certain existential presuppositions obtain (objective world).

Habermas (1984) offers the following example to illustrate these validity claims:

A seminar student understands the following request by a professor: "Please bring me a glass of water." (P. 306)

As this is not a simple imperative or sheer expression of will, but a speech act carried out in an "attitude oriented to understanding," the student may contest its validity with the following responses:

(1) No. You can't treat me like one of your employees [contesting the normative rightness of the utterance].
(2) No. You really only want to put me in a bad light in front of the other seminar participants [contesting the subjective truthfulness of the utterance].

(3) No. The next water tap is so far away that I couldn't get back before the end of the session [denying that the appropriate objective conditions obtain]. (Habermas 1984:306; comments in brackets added by author)

The student is, in the first case, contesting the action of the professor; in the second, contesting that the professor means what he says; in the third, denying the truth of propositions the professor has presupposed in the given situation. This holds, according to Habermas, for all speech acts oriented to reaching understanding.

Habermas attempts to somehow find a way to institute the binding normative (moral) conditions obtaining in the "ideal speech situation" across the entire societal community. He admits that this is, at present, a purely utopian goal, as he is unable to locate instances of communicative action at the institutional level within modern, Western society (see Sciulli 1989, 1992a, 1992b). It is, first and foremost, the problem of modernity, what Habermas refers to as the shearing off of system from the lifeworld. ${ }^{12}$ But unlike many critics of modernity, Habermas is unwilling to reject the project of Enlightenment, which he construes as the quest for the rational foundations of a critical sociology. This quest is, I believe, worthwhile and important, and hence my concern is to help reach this goal by attempting to link Habermas's analytical theory of communicative action to the empirical social world. In a somewhat more critical vein, I suggest that Habermas must take more seriously Goff-

\footnotetext{
12 In attempting to complete the project of modernity, Habermas knows full well the sorts of social pathologies that must be addressed to defend modernity against recent postmodern (meta)critiques (especially those of Lyotard, Foucault and Baudrillard). Habermas's "shearing off of the lifeworld" equates to a concern with the deleterious effects of instrumental rationality on the everyday social world (lifeworld). The ongoing rationalization of society has caused a split between system and lifeworld. This implies two forms of societal integration: (1) The lifeworld is integrated by communicative action, whereby actors work to achieve consensus through language;
} 
man's (1959, 1981, 1983a, 1983b) insights into the forms of talk that occur in the general context of human communication forged through simple co-presence (i.e., the "interaction order").

\section{BRINGING GOFFMAN BACK IN}

Habermas's concern with the problem of curtailed communication, and of communication more generally, is shared by Goffman. That is, like Habermas, Goffman spent his entire career investigating communicative action or conduct, but from an empirical or ethnographic perspective, not an overtly analytical one. In his dissertation, "Communication Conduct in an Island Community," Goffman (1953) explains, "As the study progressed, conversational interaction came to be seen as one species of social order" (p. 1). And later, citing Parsons (1951) and Barnard (1947), Goffman lays out the fundamental assumption underlying his sociological model of communication: "I assume that conversational interaction between concrete persons who are in each other's immediate presence is a species of social order and can be studied by applying the model of social order to it" (p. 33).

Whereas Habermas's rationality assumptions are explicitly stated as three validity claims, the assumption of rationality is only implicit in Goffman, as Parsons and others had already worked out sophisticated schemata to explain the place of rationality in social order, or rather, in the "constitution" of social actors operating within the social system. The closest Goffman ever comes to directly dealing with the rationality problem is through his theory of normal appearances

(2) at the systems level, functional integration intertwines action with their consequences. The latter form of integration is guided by the "objectivating attitude," the former by the "performative attitude." Because abstract and generalized criteria are encompassed in many facets of life (e.g., legal norms, economic action, the norm of cognitive rationality), the "system" may be seen as operating with a life of its own, with little or no reference to the actual activity of participants of the lifeworld. This system domination occurs through the ongoing rationalization (or what Habermas calls the "colonization") of the lifeworld. (see Goffman 1971). That is, per the dramaturgical theory of action, social actors learn-first through socialization and then through imitation and experience-the tacit cultural codes signaling an actor's proper demeanor while in the presence of others. Goffman's actor can thus modify presentations of self appropriately to "fit" any particular interaction episode so as to signal to those present that he or she is a reasoned or "rational" actor (i.e., that he or she is a ratified participant in the social proceedings, that he or she belongs there, that he or she is not "crazy" or deranged, that he or she is not a threat). An actor's minimum requirements for maintaining normal appearances through the display of his or her verbal and/or nonverbal actions means that no undue alarm is signaled to others present.

Goffman and Habermas part company on the epistemological assumptions embedded within each of their theories that pertain to each theorist's ability to conceptualize what is going on in the minds of social actors; call it the problem of Verstehen, or phenomenological "intersubjectivity," or more generally, subjective understanding. Habermas, in viewing dramaturgical action, operates explicitly with a "black box" concept of action (to be discussed more fully below). Goffman however rejects this position in his own theories. For Goffman, Habermas's view of communication is overly rationalistic. To understand this divergence, we turn to Goffman's Frame Analysis (1974), specifically his discussion of the "Frame Analysis of Talk."

\section{Goffman's Frame Analysis of Talk}

The one thing that makes the idea of communicative action possible is that, using language, disparate actors can reach consensus on issues at hand. Goffman's idea of linguistic competence is close to Habermas's: Individuals in the presence of others possess cultural competence in that they are generally able to avoid misunderstandings in their everyday communication. (Notice though, for example, the "cute mistakes" that children are allowed in their speech; they are assumed to lack a fully developed communicative competence. ) Goffman discusses conversation-the traditional view of which "assumes an easy exchange of speaker-hearer role 
[whereby participants are] engaged in a consummatory moment" (Goffman 1974:498)merely as a foil. Habermas shares this traditional, hyperrational view of conversation, and as a consequence tends to gloss over the actual social context of talk, which, I would suggest, Goffman has successfully incorporated. In other words, Habermas needs Goffman's fuller communication paradigm to flesh out his own theory of communicative action.

From Goffman's perspective, all utterances, whether formal or informal, regulative, expressive, constative, directive, commissive, or declarative-are first and foremost anchored in the surrounding world. ${ }^{13}$ As he (Goffman 1974:500) states, "utterances take up a place in the world"; they are, following Durkheim, "social facts." Utterances produce reactions or orientations of actors, thereby contributing to the production of an ongoing social world. Most important from the perspective of dramaturgy, talk is always a project imbued with "structured suspense" (Goffman 1974:506).

Suspense in talk implies that "we spend most of our time not engaged in giving information but in giving shows" (Goffman 1974: 508). The implications for Habermas's project are staggering. Habermas's theory is driven by an information paradigm. That is, social life is more or less a continuous battle over the status, the validity, the appropriateness, the truthfulness, of knowledge claimsthe problem of information exchange and transfer drives Habermas's theory. But for Goffman, talk constitutes not only bald statements of fact; talk is also about recounting, about "story-telling." Much of talk consists of replayings in which a storyteller maintains the listeners' suspense. This suspense provides frames for the organization of talk.

The purely informational perspective (Habermas) leads, in Goffman's view, to an unacceptably utilitarian view of talk or communication. The "rational recounting" of

${ }^{13}$ As Collins and Makowsky (1993:268) note, Habermas attaches one particular type of speech act, namely expressives, to Goffman's dramaturgical theory of action in that for Habermas, actors represent (or can misrepresent) their subjective states or inner selves to others through dramatic presentation. facts between participants in communication implies the black-box model of interactants (Goffman 1974:511). Furthermore, continues Goffman, "this utilitarianlike approach to speech ill equips us for what individuals actually do during speaking" (p. 512). The black-box model of information exchange is a simplification because in actuality the "insides of the actor's head are exposed in ways other than through voluntary statements or involuntary leakage" (p. 514). Going beyond the black-box model, Goffman (1974:515) gives examples of nonutilitarian talk such as "collusive communication," whereby one can "conceal speech behind speech" by conveying information via sarcasm, irony, innuendo, or simple fun. Habermas deals somewhat inadequately with the collusive frame, and would tend to write it off as strategic action, which, in any case, would not meet his standards for communicative action.

Goffman (1974) suggests that the "traditional model of the actor whose facial features are his evidential boundary does not fit the facts but instead somehow overrationalizes man" (p. 515). However, notice that an actor may guide his or her behavior to fit the black-box model-to align with normative strictures of the perceived moral universe: In Goffman's (1974) words, "he has guided his conduct so as to ensure this fit, sustaining a human nature to fit the frame" (p. 516). This is Goffman's "normal appearances," which Habermas mistakes for first-level rational action. Goffman illustrates the complexity, the frame-within-a-frame possibilities, of reasoned communication.

Additionally, Habermas says very little about what Goffman refers to as the "ritual frame of talk." This is when listener provides to speaker an intermittent stream of supportive gestures: "uh-huhs," "yeahs," nods of the head, sustaining eye contact so as to signal interest in the talk, and so forth. This ritual frame reflects the accommodating pattern of face-to-face interaction. The speaker, of course, also plays a role in accommodation, as the "life of talk consists principally of reliving," or replaying, sustained by suspense (Goffman 1974:547). In other words, naked performative utterances, such as a bridge player's bid of "three clubs," are only a minuscule element of the frame of talk. What is important, especially if we are to link Haber- 
mas's theory to the empirical social world, is that in talk a person always frames him- or herself from view. An important quote from Goffman (1974) illustrates this point:

To say that he [the speaker] assumes a role and presents himself through it is already a bias in the direction of wholeness and authenticity. What he does is to present a one-man show. He animates. (P. 547)

This animation is the speaker's agency, his or her "doing of the moment." There often are, as Habermas has rightly noted, true feelings and attitudes expressed in talk, and inner states can be documented (the famous black-box). "But," as Goffman (1974) suggests, "these displays are not some privileged access to the biological innards of the speaker, for they are properly to be attributed to a figure animated, not the animator" (p. 547). This is Goffman's (1983b) notion of "loose coupling," the difference between the mythic and the performance text-or the slippages that occur between social structure and individual human acts.

Goffman (1974) makes this extremely important point: "Everyday life, which is real enough in itself, often seems to be a laminated adumbration of a pattern or model that is itself a typification of quite uncertain realm status" (p. 562). This is what Garfinkel (1967) and others have described as the "perceived moral universe," the normative view of the world that individual actors carry around in their heads, or what Durkheim refers to as the "collective conscience." From Goffman's perspective, everyday activity provides an original against which copies can be struck.

\section{Attempting to Reconcile Goffman and Habermas}

As we have seen, Habermas's goal is to outline a research program for a universal pragmatics that identifies and reconstructs the universal conditions of possible understanding between actors. This goal, of course, turned Habermas's attention toward the realm of "practical discourse," and to specify the criteria or conditions for possible noncoerced action, this practical discourse must be aimed at "understanding" rather than at "success."
For Habermas then, "success" is an overly strategic orientation that often overrides the more crucial goal of "understanding" in action or communication. What Goffman's observations on talk help us see, however, is that Habermas's distinction between "success" and "understanding" in talk is an overspecification of a process that may be impervious, at least at this time, to the sort of analytical fine-tuning Habermas seeks. Granted, persons often "put on shows" in talk, they may attempt to deceive, and there are often calculated shifts in the alignment of speakers and hearers (what Goffman calls shifts in "footing") as the context of the talk dictates (Goffman 1981:127). But much of this seemingly "strategic" action is not necessarily oriented to success, that is, a speaker's instrumental attempt to achieve some goal at the expense of his or her audience (see Rawls 1987:143-44). In fact speakers do indeed attempt to achieve understanding through talk-Habermas's communicative actionand they utilize the props, mechanisms, and processes that Habermas erroneously condemns as evidence of a speaker's strategic or coercive intent. ${ }^{14}$

Much of the content of talk is, as Goffman shows, suffused with the very human attempt to illustrate to others through speaker's talk the presence of a stable, concerted self (see my discussion of the "negational self" [Chriss forthcoming]). In other words, everyday life is guided by fictive or romanticized ideals (norms) about the way life ought to be conducted. We learn to comport ourselves to render our activities as agreeable to others, and to show through our presentations that we have a consistent, stable persona to which our identity is connected. As Goffman (1974) suggests, "Indeed, in countless ways and ceaselessly, social life takes up and freezes

${ }^{14}$ Collins and Makowsky (1993) make much the same point, suggesting that Habermas seems to view Goffman's theory as concerned primarily with the ways that actors express or conceal subjective states before a group of others. But, as I argue here, this view of Goffman is overly narrow. Rather, "The self may be a 'sacred object' to which we give ritual respect, but by the same token it is also a modern myth which actually fluctuates with the footings one takes in different levels of social interaction" (Collins and Makowsky 1993:270; also Chriss 1993). 
into itself the understandings we have of it" (p. 563).

It is no wonder, then, that Goffman dedicated so much of his professional energies to mapping out where, how, and to what extent "real" life becomes theatrics or even downright deception. In effect, Habermas's analytical program attempts to pick up from Goffman's (and before him, Bateson's [1972]) starting point by suggesting that there is a way to make such a distinction, this being the distinction between authentic (noncoerced) and inauthentic (coerced or staged) communication.

The problem of communicative action, understood in this way, leads us to consider the following from Goffman (1974):

Life may not be an imitation of art, but ordinary conduct, in a sense, is an imitation of the proprieties, a gesture at the exemplary forms, and the primal realization of these ideals belongs more to make-believe than to reality. (P. 562)

Persons in talk, according to Goffman, always walk a tightrope along the reality/makebelieve continuum, not because there is necessarily some devious or underhanded reason for doing so, but because of the inherently tenuous and shifting positions speakers occupy while talking. Goffman's (1981:147) idea of "embedding" suggests just this; that as speakers we represent ourselves through the personal pronoun "I." As speakers we are a figure in a statement, a protagonist in a dramatic event told (or retold).

When we refer to ourselves in talk, we necessarily speak of someone who inhabits the world that is spoken about, not necessarily the world of current talk. It is first and foremost a knowledge claim, but not in the way Habermas would designate. That is, the referencing of self in talk through use of the personal pronoun allows for a tremendous flexibility of presentation(s) of self before an audience (Bell 1984). In effect, we each have at our disposal a wide array of naturally occurring dramatic personae from which to draw in normal everyday speech, and this is not alarming. ${ }^{15}$

15 For example, "hedges" and "qualifiers," in the form of performative modal verbs (e.g., I "wish," "think," "could," "hope," etc.) introduce distance between a speaker's figure and its avowal (Goffman 1981:148).
But in modern industrial societies, burgeoning populations and increased levels of anonymity are a feature of everyday interaction. In this environment, the increased flexibility and decreased accountability of selfpresentations may indeed contribute to the rise of a whole new range of framing debates, such as the imbroglios which have erupted recently over abortion, speech codes, or even sexual harassment. This particular line of investigation cannot be pursued further here because it would take us too far afield (but see Chriss 1994b; Horowitz 1993; Wiley 1994). I emphasize, however, that conceptualizations of the self, and especially the question of the sincerity of the presented self (see Tseelon 1992a), are central issues in the theory of communicative action.

\section{ISSUES OF ORGANIZATIONS AND PROFESSIONAL PRACTICE}

In summarizing my thoughts on Habermas, Goffman, and communicative action, I return now to issues of organizations and professional practice-consulting, management, evaluation, and planning. One of the areas in which sociologists can claim a degree of competence is social interaction, or more specifically, face-to-face behavior. For example, students or disciples of Goffman may choose to follow his lead regarding the observation and understanding of face-to-face interaction in naturalistic settings. For researchers so inclined, the dramaturgical theory of action provides a general framework for describing, analyzing, assessing, or explicating concrete instances of such talk in any number of settings, be it a party, an office meeting, a therapy group session, a service transaction, a chess match, a wargamers convention, or what have you.

Several years ago I spent the summer working for a large philanthropic foundation. I was hired to conduct a meta-evaluation of the foundation's evaluation research unit. Because the foundation prided itself on having a "flat" organizational hierarchy, I generally had free access to all departmental and management meetings as well as to key organizational actors, such as the executive director and the heads of the various departments (these being religion, culture, education, policy analysis, international affairs, 
communications, and evaluation). Through both formal and informal discussions with employees of the foundation, it became apparent to many of them that Goffman's work was central to my own understanding and interpretation of social behavior.

Within two weeks of my arrival, I sensed a growing uneasiness, and even suspicion, among many at the foundation. Much of this had to do, I believe, with Goffman's reputation for turning a jaundiced eye toward organizations, and organizational actors more generally, as evidenced by his infamous exposé of "total institutions" reported in Asylums (1961a). What I suggest is that many in organizations or organizational studies seem to have a one-sided or incomplete view of Goffman's theory-one that views him as overtly concerned with exposing the dark underbelly or the "crawlspaces" of organizations. ${ }^{16}$

Ingram (1986) perhaps best typifies this particular sentiment; he suggests that the notion of organizational "underlife" was first proposed by Goffman (1961a). According to Ingram's reading of Goffman, the underlife of an organization is composed of organizational members who, while maintaining a level of organizational identification and appearing to fulfill organizational roles, engage in behaviors that violate organizational expectations and yield unauthorized rewards. The crawlspace of an organization, then, is the structure of arrangements that support or even promote underlife existence.

Confronted with this rather negative assessment of Goffman at the foundation, or rather, confronted with the abiding contention that Goffman has little to offer in the way of explicating organizational behavior, my next step was to determine what literature or traditions of thought guided the dayto-day theories-in-use of these professional

16 There may also exist within organizations high levels of skepticism toward intellectuals or academicians in general, regardless of their theoretical or philosophical orientation, especially those who are not well known to members of the organization. Kanter's (1977) fieldwork appears to confirm this atmosphere of anti-intellectualism in formal organizations: "Emphasis was placed on getting along, 'keeping your nose clean,' and on having a smooth interpersonal style. Introspection was out. Intellectuals were suspect" (p. 41). practitioners, especially the evaluators and consultants at the foundation with whom I had regular contact. ${ }^{17}$

As we saw in an earlier section, a sizable portion of the research tradition guiding organizational evaluators and consultants is represented by Argyris's (1993a, 1993b; Argyris and Schon 1974, 1989) and Schon's (1983) "action research." This tradition is in turn derived from Lewin's $(1943,1951)$ research on small groups, and it is important to note here the major aims of Lewin's project. As a (psychological) social psychologist, Lewin was attempting to establish in systematic fashion the links between an individual's behavior and attitudes and certain characteristics of groups; he devoted attention to the spatial and temporal characteristics determining group stability or change. Lewin's work was originally formulated within the context of problems communities typically face with regard to attitude change, loyalty, and in-group/out-group relations.

What emerges, then, from this brief review of Lewin's program is the realization that Lewin was not satisfied merely to document or describe the vagaries of face-to-face behavior or group life; his primary goal was to understand and establish the conditions under which attitude change could be affected or facilitated. As Back (1981) explains,

The kind of group that emerges from [Lewin's] model is one that has meaning for the members and that is especially effective in producing or preventing attitude change in its members. The

${ }^{17}$ I am not implying here that Ingram's own assessment of Goffman is negative. Ingram simply points out that Goffman's work in Asylums was important and influential primarily because it documented the ways persons cope in the face of the stringent demands of a coercive organizational or social structure. An underlife then becomes a survival tactic, a way of shoring up or saving identities under siege. But academics or consultants who go into organizations with the intent of observing organizational behavior and who are known to be sympathetic to Goffman's approach may be seen by organizational actors as carrying with them an implicit assumption of the coercive nature of organizations. This, then, explains the source of suspicion and negative assessments of the research observer (and of Goffman) by organizations or their representatives. 
model thus examines the conditions under which members change and begin to exhibit attitudes and beliefs similar to the group, or to act in a similar way. ... . Lewin's interest was in investigating conditions that could produce attitude and habit changes. (Pp. 330-31)

This instrumentalist, therapeutic impulse of Lewin's work was carried over into the tradition of organizational behavior (OB), in which the aim of research is to help organizations influence change, presumably for the better. Argyris's action research (1993a, $1993 \mathrm{~b}$ ) is one such program in the applied social psychology of organizations. ${ }^{18}$

Argyris and Schon (1974) tend to view Goffman's characterization of social actors (especially his position on impression management and the presentation of self) as a fair approximation of the naturally occurring but ultimately destructive tendencies toward selfsealing, defensive, and insincere behavior. This naturally occurring Model I behavior could, according to action research, be overcome through a program that heightens organizational actors' self-realizations - that is, a program that brings actors' espoused theories more into line with their actual theories-in-use. And through this change of attitudes or behaviors, organizational learning could thereby be advanced.

Habermas's program is also based on an ameliorative plan, namely the effort to assure reasoned or noncoerced communication in the face of multiple organizational structures supporting inequality and differential power that serve to cut off the possibility of consensus or intersubjective understanding through fair discussion or argumentation. But unlike Lewin's program or the program of action research, Habermas does not see Goffman's dramaturgical theory of action as representing some fundamental, albeit flawed, description of the human condition that could somehow be overcome through a critical program of attitude change or self-realization. This is because Goffman's dramaturgy cannot assure intersubjective understanding between actors because, in Habermas's view, it has no way of providing

${ }^{18}$ Lewin's work was also influential in the development of the organizational development (OD) model of attitude or behavior change (see Aguinis 1993; Marshak 1993). access to the social (normative) world, one of Habermas's three key analytical worlds (the others being the objective and subjective worlds). In other words, communicative action can be realized only if social actors have free and undistorted access to the three validity claims of propositional truth, normative rightness, and subjective truthfulness.

\section{CONCLUSION}

How has Habermas's ameliorative program of communicative action been received in the literature on organizations and professions, and how does it compare to the reception of Goffman's work? It is safe to say that Habermas's work, and critical theory more generally, has been much more influential and more seriously discussed in these fields than has Goffman's work. ${ }^{19}$ A good example of this is Holmes's (1992) paper, entitled "The Drama of Nursing." In the recent literature on organizations and the professions, much has been made of conceiving of professions as a form of aesthetic praxis, the goal being to provide a more stable analytical foundation for the concept "profession" through the identification and linking of these so-called performative practices to the concept itself. Holmes's (1992) contrast between Goffman and critical theory is instructive for our discussion:

In contrast to Goffman's dramaturgy, which stresses the artifice of social relations and suggests a cynical view of human interactions, a critical theory of dramatic praxis introduces a normative dimension in which performance may become self-realizing and emancipatory as it aspires to the status of aesthetic practice. Conceived in such terms, nursing practice becomes a powerful form of self-expression which has the potential to become liberating for the nurse and the patient. (P. 941)

Holmes's insistence that critical theory adds a normative dimension to the understanding of actors' performances points to the same failings of the dramaturgical model identified earlier by Habermas, namely that Goffman's theory of action cannot explain

${ }^{19}$ See for example Burrell's (1994) overview of Habermas's contribution to organizational analysis. 
why actors would ever engage, or choose to engage, in norm-conformative behavior. ${ }^{20}$

Again, it should be pointed out that this incongruity between critical theory and Goffman's theory on the issue of actors' access to the validity claim that assures, or at least makes possible, appropriate social relations and normative rightness, evolves from a disagreement over the ontology of self-presentation and impression management. I have already discussed at some length Goffman's position and my own defense of him on this issue, and the reasons for this disagreement should now be clear. In the final analysis, the contention between Habermas and Goffman comes down to a fundamental question: Is the presented self a sincere self? As I suggested in my attempt to reconcile the views of Goffman and Habermas (pp. 13-14), Tseelon (1992a,

${ }^{20}$ For an even more explicit treatment of Habermas's importance to nursing practice, see Porter (1994). Even given this preference for Habermas or critical theory over Goffman among authors concerned with issues of professional practice, Habermas's program is nevertheless viewed by many as overly abstract and hopelessly detached from the empirical social world. Robinson's (1994) discussion of Habermas with respect to the field of education and pedagogy is illustrative of this sentiment: "[Habermas's] work does not provide a methodology that is applicable to the conduct or evaluation of dialogical practice. Habermas's theory of communicative action is concerned to defend an ideal of rationality, founded in the universal presuppositions of speech, and this ideal cannot be directly applied to everyday situations" (p. 72). What we need, suggests authors such as Robinson (1994), Frankford (1994), and Young (1989), is a way to move from Habermas's "universal pragmatics" to an "empirical pragmatics," the latter referring to the study of actual utterances that occur in specific social contexts. Given this emphasis on empiricizing actual speech in concrete settings, it is interesting that Goffman's work in this area (e.g., 1971, 1974, 1981, 1983a) has been largely ignored. Finally, in offering suggestions for possible resources for pursuing such a critical inquiry, Robinson (1994) points to Argyris's (1993a, 1993b; Argyris and Schon 1974) action research: "The work of Argyris offers a normative theory which is compatible with the value base of critical theory and which incorporates a methodology by which it can be applied to dialogical sequences" (p. 72). 1992b) goes a long way toward answering this question. ${ }^{21}$ Tseelon (1992a) argues that the tradition known as impression management (IM) (see Arkin 1980; Schlenker 1980; Tedeschi 1981; Tedeschi and Melburg 1984), although rooted in Goffman's (1959) seminal work on the presentation of self, has veered away from Goffman's original intent in a number of crucial ways. Most important, whereas Goffman's idea of "frontstage" and "backstage" attempted merely to illustrate how selves can be partitioned in terms of self-presentations before a variety of audiences, IM's interpretation of this partitioning is that individuals possess distinctively "true" private selves and distinctively "false" public selves. ${ }^{22}$ Goffman's actor puts on a variety of faces in various settings and before particular audiences in an effort to comport him- or herself to the exigencies of the social gathering and to uphold the definition of the situation. IM's social actor, on the other hand, has a hidden agenda as he or she goes about the business of presenting the self; there is always a concerted effort to keep a private reality from surfacing during any particular public presentation.

Tseelon (1992a) explains the disjunction between the Goffman tradition and IM as follows:

The Goffmanesque approach views people's presentational behaviour as a process of negotiation. It is a game of representation. In contrast, the position advanced by IM researchers views presentational behaviour as manipulative. According to this view people present various images of themselves as a strategic

21 Welsh (1984) argues that the presented self is a product of a capitalist society which places a premium on appearances. That is, because bureaucratic actors are constantly monitored and assessed with regard to their job performance and effectiveness, this fetish of appearance has given rise to an overweening emphasis on impression management on the part of these actors (also see Willmott 1993). This view of the actor is closer to impression managements's, and even Habermas's, more cynical view of the actor as a savvy manipulator concerned merely with working the system for the enhancement of self.

${ }^{22}$ For useful discussions of the divergence of Goffman and IM within the context of organizational behavior, see Giacalone and Beard (1994) and Rosenfeld, Giacalone, and Riordan (1994). 
move. Unlike Goffman's approach, this 'game' is not an end in itself but a means to an end of gaining benefits. It is a game of misrepresentation. (P. 116)

It is my contention that Habermas, as well as many researchers working on therapeutic approaches to improving communication and interaction practices in professions or organizations, tend to make the mistake of lumping together Goffman's work and that of IM. What Habermas and many other astute social thinkers have failed to understand clearly is that, although all deceptive presentations are staged, not all staged presentations are deceptive or geared toward obfuscation or distortion.

The theory of communicative action, then, must address two difficult and interrelated issues-one ontological, one epistemological-if it is to advance any further. With respect to ontology, the theory must specify more concretely the nature of impression management, or rather, it must be able to answer the question, to what extent is the presented self a naturally occurring aspect of human interaction? With respect to epistemology, the theory must be able to address the question, how are we to know the aims or intent of the presented self? And knowing this, how then can we reconcile the realities of impression management with the potential for communicative action contained in the analytic of the presented self?

These and others issues point the way toward a continuing refinement of the theory of communicative action and reaffirm the important role that Goffman's dramaturgical theory of action can play in achieving this end. Most significantly, the achievement of such an empirically-grounded theory of communicative action holds the potential for ushering in a new era in applied sociology, especially with respect to the study and explication of organizational behavior and communication.

In fact, I envision a refinement of the Habermas-Goffman communicative action schema which could eventually serve as the basis for a clinical sociology practice. This professional practice would involve helping people, groups, or organizations that are having difficulty-communicative or otherwise-in their daily relationships. This would not be a counseling service per se, as would be typical of social work or psychotherapeutic practice (see Kubacki 1994), but would involve applying the skills of Verstehen to everyday situations, stressing the social or cultural factors, rather than the individual, psychological, or symptomological factors, implicated in such disturbances. I hope to develop and present this applied schema in a future work.

James J. Chriss recently completed his Ph.D. in sociology at the University of Pennsylvania. His main areas of interest are sociological theory, criminology, and organizational behavior. His current projects include a study of how males and females differ in their attitudes toward participation in popular dance, the sociology of consulting in organizations, embezzlement as an ongoing practical accomplishment, and getting Erving Goffman's dissertation published.

\section{REFERENCES}

Adorno, T. W., Else Frenkel-Brunswik, Daniel J. Levinson, and R. Nevitt Sanford. 1950. The Authoritarian Personality. New York: Harper and Brothers.

Agger, Ben. 1992. The Discourse of Domination: From the Frankfurt School to Postmodernism. Evanston, IL: Northwestern University Press.

Aguinis, Herman. 1993. "Action Research and Scientific Method: Presumed Discrepancies and Actual Similarities." Journal of Applied Behavioral Science 29:416-31.

Argyris, Chris. 1993a. On Organizational Learning. Cambridge, MA: Blackwell.

1993b. Knowledge for Action. San Francisco, CA: Jossey-Bass.

Argyris, Chris, Robert Putnam, and Diana McLain Smith. 1985. Action Science. San Francisco, CA: Jossey-Bass.

Argyris, Chris and Donald A. Schon. 1974. Theory in Practice: Increasing Professional Effectiveness. San Francisco, CA: Jossey-Bass.

. 1989. "Participatory Action Research and Action Science Compared." American Behavioral Scientist 32:612-23.

Arkin, Robert M. 1980. "Self-Presentation." Pp. 158-82 in The Self in Social Psychology, edited by D. M. Wegner and R. M. Vallacher. Oxford, England: Oxford University Press.

Back, Kurt W. 1981. "Small Groups." Pp. 32043 in Social Psychology: Sociological Perspectives, edited by M. Rosenberg and R. H. Turner. New York: Basic Books.

Baldamus, Willhelm. 1992. "Understanding Habermas's Methods of Reasoning." History of 
the Human Sciences 5:97-115.

Barnard, Chester I. 1947. The Functions of the Executive. Cambridge, MA: Harvard University Press.

Bateson, Gregory. 1972. Steps to an Ecology of Mind. New York: Ballantine.

Bell, Allan. 1984. "Language Style as Audience Design." Language in Society 13:145-204.

Benhabib, Seyla. 1992. Situating the Self: Gender, Community and Postmodernism in Contemporary Ethics. New York: Routledge.

Bottomore, Tom. 1984. The Frankfurt School. London, England: Tavistock.

Burrell, Gibson. 1994. "Modernism, Postmodernism and Organizational Analysis 4: The Contribution of Jurgen Habermas." Organization Studies 15:1-19.

Chriss, James J. 1992. "Habermas and Goffman: Some Suggestions for Future Research." Perspectives: The Theory Section Newsletter 15:6. 1993. "Durkheim's Cult of the Individual as Civil Religion: Its Appropriation by Erving Goffman." Sociological Spectrum 13:251-75.

_. 1994a. "Goffman, Parsons, and Contemporary Sociology: Working towards Integration." Ph.D. dissertation. Department of Sociology, University of Pennsylvania, Philadelphia, PA.

. 1994b. "Spain on Status and Space: A Comment." Sociological Theory 12:106-109.

_. Forthcoming. "Role Distance and the Negational Self." In Goffman's Patrimony, edited by G. W. H. Smith. London, England: Routledge.

Collins, Randall and Michael Makowsky. 1993. The Discovery of Society. 5th ed. New York: McGraw-Hill.

Cooke, Maeve. 1994. Language and Reason: $A$ Study of Habermas's Pragmatics. Cambridge, MA: MIT Press.

Dahl, Goran. 1995. "Critique, Conservatism, Ideology: The Frankfurt School's Critique of the Sociology of Knowledge Revisited." Pp. 15579 in Current Perspectives in Social Theory, vol. 15, edited by B. Agger. Greenwich, CT: JAI Press.

Dahrendorf, Ralf. 1958. "Out of Utopia: Toward a Reorientation of Sociological Analysis." American Journal of Sociology 64:115-27.

Felts, Arthur A. 1992. "Organizational Communication: A Critical Perspective." Administration and Society 23:495-513.

Forester, John. 1989. Planning in the Face of Power. Berkeley, CA: University of California Press.

2. 1992. "Critical Ethnography: On Fieldwork in a Habermasian Way." Pp. 46-65 in Critical Management Studies, edited by $M$. Alvesson and $\mathrm{H}$. Willmott. London, England: Sage.
Frankford, David M. 1994."'The Critical Potential of the Common Law Tradition" (Review Essay of David Sciulli's Theory of Societal Constitutionalism). Columbia Law Review 94:1076123.

Garfinkel, Harold. 1967. Studies in Ethnomethodology. Englewood Cliffs, NJ: Prentice-Hall.

Giacalone, Robert A. and Jon W. Beard. 1994. "Impression Management, Diversity, and International Management." American Behavioral Scientist 37:621-36.

Goffman, Erving. 1953. "Communication Conduct in an Island Community." Ph.D. dissertation. Department of Sociology, University of Chicago, Chicago, IL.

1959. The Presentation of Self in Everyday Life. New York: Doubleday Anchor.

- 1961a. Asylums: Essays on the Social Situation of Mental Patients and Other Inmates. Garden City, NY: Doubleday Anchor.

. 1961b. Encounters: Two Studies in the Sociology of Interaction. Indianapolis, IN: Bobbs-Merrill.

1963a. Behavior in Public Places: Notes on the Social Organization of Gatherings. New York: Free Press

1963b. Stigma: Notes on the Management of Spoiled Identity. Englewood Cliffs, NJ: Prentice-Hall.

1967. Interaction Ritual: Essays on Face-to-Face Behavior. Garden City, NY: Doubleday Anchor. 1969. Strategic Interaction. Philadelphia, PA: University of Philadelphia Press.

1971. Relations in Public: Microstudies of the Public Order. New York: Basic Books.

. 1974. Frame Analysis: An Essay on the Organization of Experience. Boston, MA: Northeastern University Press.

$787-815$.

1978. "Response Cries." Language 54:

1981. Forms of Talk. Philadelphia, PA: University of Pennsylvania Press

1983a. "Felicity's Condition." American Journal of Sociology 89:1-53.

. 1983b. "The Interaction Order." American Sociological Review 48:1-17.

Gouldner, Alvin W. 1970. The Coming Crisis of Western Sociology. New York: Basic Books.

Grice, H. P. 1975. "Logic and Conversation." Pp. 64-75 in The Logic of Grammar, edited by D. Davidson and G. Harman. Encino, CA: Dickenson.

Habermas, Jurgen. 1971. Knowledge and Human Interests. Translated from German by J. J. Shapiro. Boston, MA: Beacon Press.

1975. Legitimation Crisis. Translated from German by T. McCarthy. Boston, MA Beacon Press.

. 1979. "Comments on Papers by Ekman 
and Goffman." Pp. 241-45 in Human Ethology: Claims and Limits of a New Discipline, edited by $M$. von Cranach, K. Foppa, W. Lepenies, and D. Ploog. Cambridge, England: Cambridge University Press.

1984. The Theory of Communicative Action. Vol. 1. Translated from German by $T$. McCarthy. Boston, MA: Beacon Press.

1987. The Theory of Communicative Action. Vol. 2. Translated from German by $T$. McCarthy. Boston, MA: Beacon Press.

Hakel, Milton D. 1994. "The Past, Present, and Future of $\mathrm{OB}$ Applications by Consulting Academicians." Pp. 275-87 in Organizational Behavior: The State of the Science, edited by J. Greenberg. Hillsdale, NJ: Erlbaum.

Hayim, Gila J. 1992. "Naturalism and the Crisis of Rationalism in Habermas." Social Theory and Practice 18:187-209.

Hinkle, Gisela J. 1992. "Habermas, Mead, and Rationality." Symbolic Interaction 15:315-31.

Holmes, Colin A. 1992. "The Drama of Nursing." Journal of Advanced Nursing 17:941-50.

Horowitz, Irving L. 1993. The Decomposition of Sociology. New York: Oxford University Press.

House, Robert, Denise M. Rousseau, and Melissa Thomas-Hunt. 1995. "The Meso Paradigm: A Framework for the Integration of Micro and Macro Organizational Behavior." Pp. 71-114 in Research in Organizational Behavior, vol. 17, edited by L. L. Cummings and B. M. Staw. Greenwich, CT: JAI Press.

Ingram, Larry C. 1986. "In the Crawlspace of the Organization." Human Relations 39:157-86.

Kanter, Rosabeth Moss. 1977. Men and Women of the Corporation. New York: Basic Books.

Kincheloe, Joe L. and Peter L. McLaren. 1994. "Rethinking Critical Theory and Qualitative Research." Pp. 138-57 in Handbook of Qualitative Research, edited by N. K. Denzin and Y. S. Lincoln. Thousand Oaks, CA: Sage.

Kingwell, Mark. 1993. "Is It Rational to Be Polite?" Journal of Philosophy 90:387-404.

Kubacki, Steven R. 1994."Applying Habermas's Theory of Communicative Action to Values in Psychotherapy." Psychotherapy 31:463-77.

Ledoux, Yves. 1981. "Theorie critique et recherche-action: l'heritage habermassien" (Critical Theory and Action Research: The Habermasian Heritage). Revue de l'Institut de Sociologie 3:623-35.

Lewin, Kurt. 1943. "Defining 'The Field of a Given Time."'Psychological Review 50:292310.

1951. Field Theory in Social Science: Selected Theoretical Papers. New York: Harper.

Lidz, Victor M. 1986. "Parsons and Empirical Sociology." Pp. 141-82 in The Nationalization of the Social Sciences, edited by S. Z. Klausner and V. M. Lidz. Philadelphia, PA: University of Pennsylvania Press.

Marshak, Robert J. 1993. "Lewin Meets Confucius: A Re-View of the OD Model of Change." Journal of Applied Behavioral Science 29:393-415.

Mills, C. Wright. 1959. The Sociological Imagination. London, England: Oxford University Press.

Munch, Richard. 1993. Sociological Theory. Vol 2. Chicago, IL:Nelson-Hall.

Parsons, Talcott. 1937. The Structure of Social Action. New York: Free Press.

Press. 1951. The Social System. New York: Free

- 1978. Action Theory and the Human Condition. New York: Free Press.

Porter, Sam. 1994. "New Nursing: The Road to Freedom?" Journal of Advanced Nursing 20:269-74.

Rawls, Anne W. 1987. "The Interaction Order Sui Generis: Goffman's Contribution to Social Theory." Sociological Theory 5:136-49.

Robinson, Viviane M. J. 1994. "The Practical Promise of Critical Research in Educational Administration." Educational Administration Quarterly 30:56-76.

Rosenfeld, Paul, Robert A. Giacalone, and Catherine A. Riordan. 1994. "Impression Management Theory and Diversity: Lessons for Organizational Behavior." American Behavioral Scientist 37:601-04.

Rosenthal, John. 1992. "What Is Life? A Habermas Critique." Social Science Information 31:5-42.

Schlenker, Barry R. 1980. Impression Management. Monterey, CA: Brooks/Cole.

Schon, Donald A. 1983. The Reflective Practitioner. New York: Basic Books.

Schroyer, Trent. 1973. The Critique of Domination. Boston, MA: Beacon.

Sciulli, David. 1989. "Analytical Limits of Communicative Action: Two Requirements of Habermas' Critical Theory and of Societal Constitutionalism." Current Perspectives in Social Theory 9:55-90.

- 1992a. Theory of Societal Constitutionalism: Foundations of a Non-Marxist Critical Theory. New York: Cambridge University Press.

1992b. "Habermas, Critical Theory, and the Relativistic Predicament." Symbolic Interaction 15:299-313.

Scott, Robert A. 1969. The Making of Blind Men. New York: Russell Sage Foundation.

Stein, Howard F. 1994. Listening Deeply: An Approach to Understanding and Consulting in Organizational Culture. Boulder, CO: Westview Press.

Tedeschi, James T., ed. 1981. Impression Man- 
agement Theory and Social Psychological Research. New York: Academic Press.

Tedeschi, James T. and Valerie Melburg. 1984. "Impression Management and Influence in the Organization." Pp. $31-58$ in Research in the Sociology of Organizations, vol. 3, edited by S. B. Bacharach and E. J. Lawler. Greenwich, CT: JAI Press.

Torbert, William R. 1991. The Power of Balance: Transforming Self, Society, and Scientific Inquiry. Newbury Park, CA: Sage.

Tseelon, Efrat. 1992a. "Is the Presented Self Sincere? Goffman, Impression Management and the Postmodern Self." Theory, Culture and Society 9:115-28.

1992b. "Self-Presentation through Appearance: A Manipulative vs. a Dramaturgical Approach." Symbolic Interaction 15:501-13.

von Cranach, M., K. Foppa, W. Lepenies, and D. Ploog, eds. 1979. Human Ethology: Claims and
Limits of a New Discipline. Cambridge, England: Cambridge University Press.

Welsh, John F. 1984. "The Presentation of Self in Capitalist Society: Bureaucratic Visibility as a Social Source of Impression Management." Humanity and Society 8:253-71.

Whyte, William Foote. 1991. Participatory Action Research. Newbury Park, CA: Sage.

Wiley, Norbert. 1994. The Semiotic Self. Chicago, IL: University of Chicago Press.

Willmott, Hugh. 1993. "Strength Is Ignorance, Slavery Is Freedom: Managing Culture in Modern Organizations." Journal of Management Studies 30:515-52.

Wrong, Dennis H. 1961. "The Oversocialized Conception of Man in Modern Sociology." American Sociological Review 26:183-93.

Young, Robert E. 1989. A Critical Theory of Education: Habermas and Our Children's Future. New York: Harvester Wheatsheaf. 